\title{
Building Sustainability in New and Existing Concrete Structures with FRP
}

\author{
Shamim A. Sheikh, Professor \\ Department of Civil and Mineral Engineering, University of Toronto \\ shahria.alam@ubc.ca
}

\begin{abstract}
The annual cost of corrosion of steel in all its forms is estimated at about $3 \%$ of the world's GDP.

A substantial part of that, approximately $0.5 \%$ of GDP, is related to infrastructure damage that amounts to over $\$ 400$ billion every year. The need to find a solution to address this constant drain on national economies is thus urgent and requires a two-pronged approach. The first part is to find an economical and feasible solution for the rehabilitation of damaged corroded structures as shown in the picture and the second is to find a non-corroding replacement of steel in new structures.

The research underway at the University of Toronto and summarized in this paper is focused on both these aspects. The materials used and discussed here are glass and carbon fibre reinforced polymers (GFRP and CFRP). The experimental part of this research program involves testing of small-scale to full scale columns, beams, slabs and frames under realistic loads to simulate field behaviour. The analytical component of this research includes development of models to predict

Structural behaviour and procedures for the design of members with FRP reinforcement. The larger specimens tested included $500 \mathrm{~mm}$ diameter columns, $400 \times 650 \mathrm{~mm}$ cross section beams, $200 \mathrm{~mm}$ thick slab and a scaled model of a frame. To simulate the damage in the field, some of the specimens were corroded in the lab and retrofitted with glass or carbon FRP. Use of external FRP was investigated for its efficacy in upgrading structures for confinement, flexure and shear. New structural specimens were reinforced in one of the three ways; all steel, all FRP or hybrid reinforcement with steel and FRP distributed to utilize the best features of each material. In hybridreinforced specimens, the outer layers of reinforcement were of FRP and the steel was embedded deeper into the concrete to safeguard against corrosion.

Results from this research show excellent performance of FRPs as reinforcement for concrete structures. In many cases, their performance was found to be superior to that of steel such as for confinement of concrete for seismic resistance. A number of design codes and specifications have been developed and are being updated regularly in Canada and elsewhere which is helping accelerate the use of FRP for sustainable infrastructure. The procedures developed in this research have been applied in the field and the structures have been monitored for their long-term performance, in some cases for up to 10 years.

The presentation will include a summary of the research carried out over the last decade or so. Results from the current ongoing study on the effects of climate change on FRP-reinforced structures will also be presented including the fire tests on columns carrying service loads.
\end{abstract}

